\title{
Birth Weight is Associated with Body Composition in a Multiethnic Pediatric Cohort
}

\author{
Amanda L. Willig ${ }^{*}$, , Lynae J. Hanks ${ }^{1}$, Jose R. Fernandez ${ }^{1,2}$ \\ ${ }^{I}$ Department of Nutrition Sciences and the Clinical Nutrition Research Center, ${ }^{2}$ Department of Biostatistics, Section on \\ Statistical Genetics, University of Alabama at Birmingham, 1675 University Blvd, WEBB 429, Birmingham, AL 35294, \\ USA
}

\begin{abstract}
Several studies have indicated that birth weight is associated with increased risk for excess fat accumulation later in life. Our objective was to evaluate the association between birth weight and body composition measures in a multiethnic pediatric population while controlling for environmental factors previously associated with increased adiposity. Dual-energy x-ray absorptiometry was performed on 256 European-American, African-American, and Hispanic-American boys and girls. Body composition measurements were adjusted by height to create a fat mass index, fat-free mass index, and trunk fat mass index. After adjusting for age, pubertal status, sex, race/ethnicity, socioeconomic status, and physical activity, we found that higher birth weights were associated with significant increases in all three body composition indices $(\mathrm{P}<0.05)$. After adjusting for physical activity in analysis of covariance, the relationship between birth weight and the fat-free mass index was no longer significant. This study suggests that higher birth weight is a risk factor for later unfavorable body composition changes in children, and that current environment and physical activity habits can affect these outcomes.
\end{abstract}

Keywords: Birth weight, pediatric, adiposity, fat mass index, fat-free mass index.

\section{INTRODUCTION}

Scientists have proposed that the intrauterine environment can influence adult health outcomes, particularly those related to obesity such as cardiovascular disease and type 2 diabetes [1-3]. Low birth weight $(<2500 \mathrm{~g})$, an indicator of the intrauterine environment, is linked to risk for these chronic diseases [4-6]. Paradoxically, additional studies suggest that a high birth weight (macrosomia; > $4000 \mathrm{~g}$ ) is related to increased body mass index (BMI) and body weight, which may also increase risk for type 2 diabetes and cardiovascular disease [7-9]. Although the etiology of obesity is difficult to disentangle, a contribution of the intrauterine environment is likely.

Most studies investigating the association between birth weight and body size have used BMI or other anthropometric measures as proxy measures for body "fatness". However, among children it is unclear whether these associations with BMI are due to greater fat mass or fat-free mass. Ageadjusted BMI in children is more related to lean mass and can overestimate actual body fat in taller children, while underestimating fatness in shorter children [10-13]. More precise measurements of fat mass and fat-free mass, adjusted for height ${ }^{2}$, can provide independent, more accurate indicators of leanness, fatness, and central adiposity in children [14].

Environmental/behavioral components may interact with birth outcomes to modify body composition. However,

*Address correspondence to this author at the Department of Nutrition Sciences, University of Alabama at Birmingham, 1675 University Blvd, WEBB 429, Birmingham, AL 35294, USA; Tel: +1 205975 9678; E-mail: mandyrd@uab.edu previous studies relating birth weight to pediatric body composition often lack environmental/behavioral measures that also affect current body mass. Physical activity and dietary intake are associated with pediatric fat and fat-free mass, as well as central adiposity [15,16]. Additionally, socioeconomic status (SES) serves as an indicator of environmental status, with lower SES associated with worse health outcomes in children [17]. Hence, the aim of this study was to evaluate the relationship between birth weight and more precise measures of fat mass, fat-free mass, and central adiposity, while controlling for environmental/ behavioral factors that could also influence current body composition in a multiethnic pediatric population.

\section{MATERIALS AND METHODOLOGY}

Participants included 256 children aged 7-12 years and classified by parental self-report as African-American (AA), European-American (EA), or Hispanic-American (HA). Data includes all children measured as part of an on-going crosssectional study between 2004 and 2008 designed to evaluate genetic associations with diabetes risk factors. Children were recruited with community fliers and presentations, and newspaper advertisements. The participants were required to have no medical diagnoses that were contraindicative to study participation (including hypercholesterolemia, diabetes, or hypertension) and were not taking any medications known to affect body composition levels. During the study visits, body composition and anthropometric measurements were taken, and birth weight was obtained by parental report. Children were instructed to wear an accelerometer for 7 days to record physical activity levels. A 24-hour diet recall was administered at each visit using the triple-pass method. 
Physician exam determined pubertal status to be $\leq 3$ according to the criteria of Marshall and Tanner [18,19]. The study was approved by the University of Alabama at Birmingham (UAB) Institutional Review Board for Human Use, with children and parents providing informed written consent prior to participation.

\section{Body Composition}

Body weight was measured to the nearest $0.1 \mathrm{~kg}$ in light clothing without shoes (Scale-tronix 6702W; Scale-tronix, Carol Stream, IL), and height was determined using a mechanical stadiometer. Body mass index (weight $(\mathrm{kg}) /$ height $\left(\mathrm{m}^{2}\right)$ ) was calculated from these values. Total fat mass, trunk fat mass, and total fat-free mass were evaluated via dual energy x-ray absorptiometry (DXA) with a GE Lunar Prodigy densitometer (Lunar Radiation Corp., Madison, WI). Subjects were scanned in light clothing while lying flat on their backs with arms at their sides. DXA scans were analyzed with pediatric software enCORE 2002 version 6.10.029. Values were used to calculate the fat mass index (FMI; fat mass $(\mathrm{kg}) /$ height $\left(\mathrm{m}^{2}\right)$ ), trunk fat index (trunk FMI), and fat-free mass index (FFMI; fat-free mass $(\mathrm{kg}) /$ height $\left.\left(\mathrm{m}^{2}\right)\right)$.

\section{Socioeconomic Status}

Socioeconomic status (SES) was measured with the Hollingshead 4-factor index of social class, which combines the educational attainment and occupational prestige for the number of working parents in the child's family. Scores ranged from 8 to 66 , with the higher scores indicating higher theoretical social status [20].

\section{Diet recalls and Physical Activity}

A registered dietitian administered two 24-hour diet recalls using the triple-pass method. Both parent and child participated during the recalls. Data was entered into the Nutrition Data System for Research software version 2006
(Nutrition Coordinating Center, University of Minnesota, Minneapolis), and values from the two visits were averaged for analysis. Average intakes of several variables, including total caloric intake and percentage calories from carbohydrate, fat, protein, and sugar were analyzed for this study.

Physical activity levels were recorded with a uniaxial ActiGraph accelerometer (GT1M - Standard Model 1980100-02, ActiGraph LLC, Pensacola, FL). Actigraph monitors have been shown to exhibit high inter-instrument reliability [21]. Epoch length was set at one minute and data expressed as counts per minute (counts $\mathrm{min}^{-1}$ ). Children wore the monitors on and elastic belt at the waist, over the right hip, for seven full days prior to the overnight stay. They were instructed to only remove the monitor during bathing, swimming, or sleeping. Daily counts were analyzed as average time (minutes/day) spent on moderate and vigorous physical activities (MVPA).

\section{Statistical Analysis}

Birth weight was divided into quintiles for analyses, with quintile 1 composed of children with low birth weight $(<$ $2500 \mathrm{~g}$ ), and quintile 5 composed mainly of children with a high birth weight $(>4000 \mathrm{~g})$. Descriptive statistics were analyzed by quintile of birth weight using analysis of variance (ANOVA) with Tukey's post-hoc test. After failing to conform to tests for normality, the following variables were log-transformed for analyses: total fat mass, total fatfree mass, trunk fat mass, BMI, and BMI percentile. Analysis of covariance (ANCOVA) was used to evaluate the effect of birth weight quintile on these variables after controlling for height, age, pubertal status, sex, SES, and MVPA. Additionally, ANCOVA was utilized to determine the association of birth weight with FMI, FFMI, and trunk FMI controlling for the covariates age, pubertal status, sex, SES, and MVPA. After confirming a linear relationship of birth weight $(\mathrm{g})$ with body composition variables, linear regression analysis was used to evaluate the association

Table 1. Characteristics of Study Participants by Birth Weight Quintile

\begin{tabular}{|c|c|c|c|c|c|}
\hline & $\begin{array}{l}\text { Quintile 1 } \\
(n=50)\end{array}$ & $\begin{array}{l}\text { Quintile } 2 \\
(n=52)\end{array}$ & $\begin{array}{c}\text { Quintile 3 } \\
(n=52)\end{array}$ & $\begin{array}{c}\text { Quintile } 4 \\
(n=51)\end{array}$ & $\begin{array}{l}\text { Quintile } 5 \\
(n=51)\end{array}$ \\
\hline Age & $9.6 \pm 1.6$ & $9.5 \pm 1.5$ & $9.4 \pm 1.6$ & $9.5 \pm 1.6$ & $9.6 \pm 1.7$ \\
\hline Ethnicity(EA/AA/HA) & $8 / 23 / 19$ & $17 / 19 / 16$ & $31 / 14 / 7$ & $26 / 15 / 10$ & $24 / 16 / 11 *$ \\
\hline Sex $(n, \%$ male $)$ & $26(52 \%)$ & $23(43 \%)$ & $26(50 \%)$ & $34(64 \%)$ & $27(53 \%)$ \\
\hline Tanner Stage $(1 / 2 / 3)$ & $30 / 9 / 11$ & $30 / 13 / 9$ & $40 / 8 / 4$ & $37 / 11 / 3$ & $25 / 18 / 8 *$ \\
\hline Height $(\mathrm{cm})$ & $138.5 \pm 11.8$ & $139.3 \pm 10.1$ & $138.0 \pm 8.8$ & $139.4 \pm 10.7$ & $141.5 \pm 12.1$ \\
\hline Weight $(\mathrm{kg})$ & $35.2 \pm 9.7$ & $35.4 \pm 8.4$ & $34.6 \pm 7.2$ & $37.0 \pm 10.7$ & $39.6 \pm 10.2$ \\
\hline Birth Weight (kg) & $2.3 \pm 0.4$ & $3.0 \pm 0.1$ & $3.3 \pm 0.1$ & $3.6 \pm 0.1$ & $4.1 \pm 0.3 \dagger$ \\
\hline BMI $\left(\mathrm{kg} / \mathrm{m}^{2}\right)$ & $18.1 \pm 2.9$ & $18.0 \pm 2.5$ & $18.0 \pm 2.6$ & $18.8 \pm 3.5$ & $19.5 \pm 2.8 *$ \\
\hline BMI percentile & $62.4 \pm 27.9$ & $62.8 \pm 25.7$ & $64.0 \pm 26.3$ & $65.5 \pm 29.1$ & $75.7 \pm 20.6$ \\
\hline Fat mass (kg) & $8.2 \pm 5.5$ & $8.2 \pm 4.7$ & $7.7 \pm 4.0$ & $9.1 \pm 7.0$ & $10.3 \pm 6.1$ \\
\hline FMI $\left(\mathrm{kg} / \mathrm{m}^{2}\right)$ & $4.2 \pm 2.3$ & $4.1 \pm 2.0$ & $4.0 \pm 2.1$ & $4.5 \pm 3.0$ & $5.1 \pm 2.6$ \\
\hline Fat-free mass (kg) & $24.9 \pm 6.0$ & $24.9 \pm 5.0$ & $25.1 \pm 4.9$ & $25.8 \pm 4.6$ & $27.0 \pm 5.8$ \\
\hline FFMI $\left(\mathrm{kg} / \mathrm{m}^{2}\right)$ & $12.9 \pm 1.4$ & $12.8 \pm 1.3$ & $13.1 \pm 1.4$ & $13.3 \pm 1.2$ & $13.4 \pm 1.2$ \\
\hline Trunk fat (kg) & $3.4 \pm 2.7$ & $3.3 \pm 2.3$ & $3.0 \pm 1.9$ & $3.8 \pm 3.4$ & $4.2 \pm 2.9$ \\
\hline Trunk FMI $\left(\mathrm{kg} / \mathrm{m}^{2}\right)$ & $1.7 \pm 1.2$ & $1.7 \pm 1.0$ & $1.6 \pm 1.0$ & $1.9 \pm 1.5$ & $2.1 \pm 1.3$ \\
\hline SES & $34.4 \pm 13.4$ & $35.1 \pm 13.6$ & $43.6 \pm 13.6$ & $39.2 \pm 15.1$ & $40.6 \pm 15.3 \dagger$ \\
\hline MVPA (min/d) & $52.6 \pm 37.2$ & $57.2 \pm 32.5$ & $60.2 \pm 31.6$ & $68.8 \pm 32.4$ & $57.5 \pm 31.5$ \\
\hline
\end{tabular}


between these factors controlling for the covariates listed above. All analyses were performed using SAS version 9.2 (SAS Institute, Cary, NC) with a significance level of $\mathrm{P}<$ 0.05 .

\section{RESULTS}

Participants who exceeded 3.5 standard deviations from the mean birth weight $(n=2)$ were removed from the analysis to avoid bias in the current analyses. Descriptive statistics are presented in Table 1. A greater number of AA and HA children were in the lower quintiles of birth weight (quintiles 1 and 2). Children in the highest quintile of birth weight (quintile 5) were reproductively more mature $(\mathrm{P}<$ 0.05) when participating in the study independent of gender or race/ethnicity. Children in quintile 3 had a greater SES level than all other groups $(\mathrm{P}<0.01)$, and children in quintiles 4 and 5 exhibited a higher BMI compared to the other groups $(\mathrm{P}<0.05)$. There were no other differences in body composition in unadjusted ANOVA models.

After controlling for covariates, no dietary variables contributed to differences in body composition and were subsequently removed from the models. A significant difference by birth weight quintile was noted for BMI $\left(\mathrm{r}^{2}=0.29, \mathrm{P}<\right.$ $0.01)$, BMI percentile $\left(\mathrm{r}^{2}=0.27, \mathrm{P}<0.01\right)$, and fat mass $\left(\mathrm{r}^{2}=\right.$ $0.35, \mathrm{P}<0.01)$. A significant difference by quintile was noted in fat-free mass $\left(\mathrm{r}^{2}=0.69, \mathrm{P}<0.02\right)$; however, this difference was not significant when physical activity (MVPA) was added to the model. When indexed variables were analyzed, FMI and trunk FMI significantly differed by birth weight quintile (Fig. 1, p < 0.01). FFMI differed by birth weight quintile when not controlling for MVPA; however, there was no difference by quintile after including MVPA as a model covariate.

When linear regression was used to assess the relationship between birth weight (g) and body composition variables, birth weight was positively associated with fat mass, BMI, BMI percentile, and fat-free mass (all at $\mathrm{p}<0.01$ ) after controlling for covariates. A positive association with birth weight was also observed for FMI $(\mathrm{p}<0.01)$, FFMI $(\mathrm{p}=$ $0.02)$, and trunk FMI ( $<<0.01$; Table 2).

Table 2. Association of Birth Weight with Fat Mass Index (FMI), Fat-Free Mass Index (FFMI), and Trunk FMI*

\begin{tabular}{|c|c|c|c|c|c|c|}
\hline \multirow[b]{2}{*}{ Covariates } & \multicolumn{2}{|c|}{ FMI } & \multicolumn{2}{|c|}{ FFMI } & \multicolumn{2}{|c|}{ Trunk FMI } \\
\hline & B & $\mathbf{p}$ & B & $\mathbf{p}$ & B & $\mathbf{p}$ \\
\hline Birth weight (g) & 0.01 & $<0.01$ & $<0.01$ & 0.02 & 0.61 & $<0.01$ \\
\hline Age (years) & -0.03 & 0.83 & 0.04 & 0.49 & -0.18 & 0.55 \\
\hline Pubertal status & 0.64 & 0.02 & 0.69 & $<0.01$ & 0.18 & 0.02 \\
\hline Female sex & 0.21 & 0.52 & -1.08 & $<0.01$ & 0.18 & 0.03 \\
\hline AA ethnicity & -0.71 & 0.08 & 0.41 & 0.05 & -0.24 & 0.02 \\
\hline HA ethnicity & 1.05 & 0.03 & 0.33 & 0.18 & 0.36 & $<0.01$ \\
\hline SES & -0.03 & 0.02 & $<0.01$ & 0.56 & -0.26 & 0.02 \\
\hline MVPA (min/day) & -0.02 & $<0.01$ & $<0.01$ & 0.06 & -0.16 & 0.02 \\
\hline
\end{tabular}
$\mathrm{MVPA}=$ moderate/vigorous physical activity .

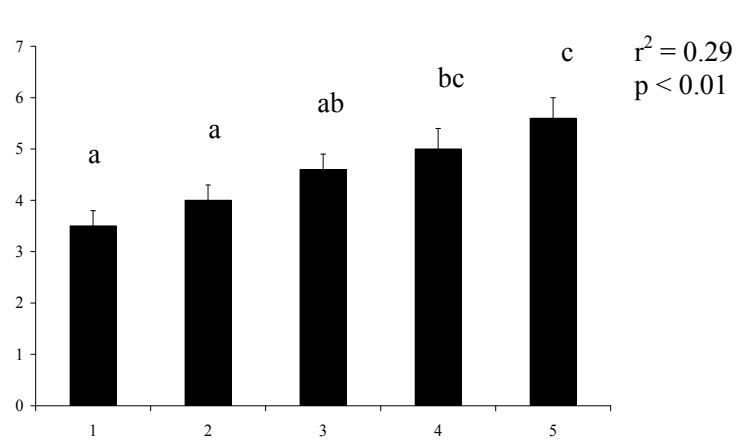

a. Fat Mass Index

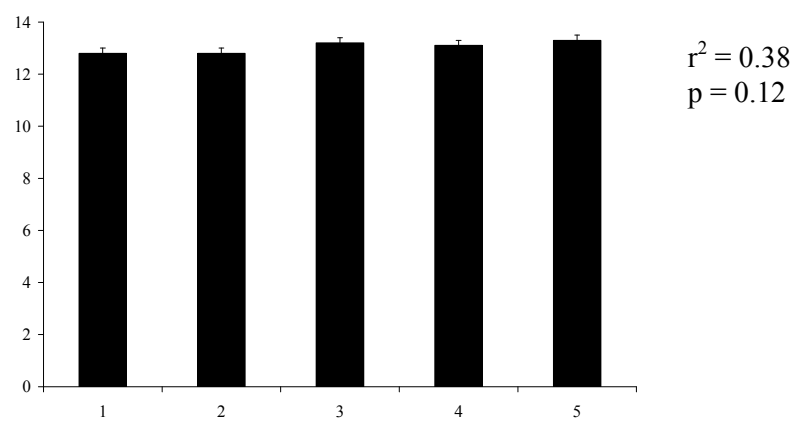

b. Fat-Free Mass Index

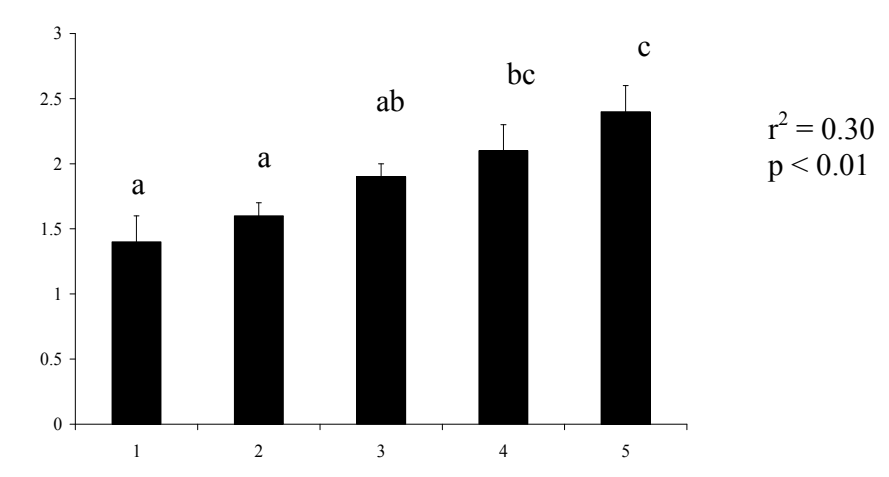

c. Trunk Fat Mass Index

Fig. (1). Least square means fat mass index (FMI), fat-free mass index (FFMI), and trunk FMI by birth weight quintile*

*All models adjusted for age, pubertal status, sex, socioeconomic status, physical activity. ${ }^{\text {a,b,c }}$ superscripts indicate group differences. 
Additional covariates were also associated with the three indices. Greater pubertal status (higher Tanner stage) was positively associated with FMI, FFMI, and trunk FMI ( $\mathrm{p}<$ 0.05 ). Hispanic ethnicity was related to a higher FMI and trunk FMI while SES and MVPA were negatively associated with FMI and trunk FMI (all at $\mathrm{p}<0.05$ ). Additionally, female sex was associated with a lower FFMI and greater trunk FMI.

\section{DISCUSSION}

Our results indicate that birth weight is positively associated with body composition among children ages 7-12 years, and that these relationships are independent of age, pubertal status, sex, physical activity, and SES. Additionally, we show that controlling for physical activity attenuates the relationship of birth weight with FFMI. These results suggest that the intrauterine environment may affect later body composition of the child, and additional studies are needed to improve methods of detecting mothers at-risk for having macrosomic babies. The association of environmental factors with current pediatric FMI and trunk FMI indicate that interventions designed to attenuate fat mass gain could benefit children born at a high birth weight.

Studies using BMI as a proxy for body fat have shown equivocal results in the relationship between body composition and birth weight among children and adults [22,23]. However, BMI does not distinguish fat mass from fat-free mass, and may be an imprecise measure of adiposity in children [12]. Our use of the FMI allowed us to evaluate the relationship of birth weight with body fat independent of the associations with fat-free mass or height. Our finding that higher birth weight predicted a greater FMI is consistent with the results of Whitaker et al. [9], who noted a greater percentage of obesity among children born at a high birth weight [10]. Similarly, we note that birth weight was positively associated with trunk FMI, which is an indicator of central adiposity. Central adiposity is linked to greater risk for the metabolic syndrome [24,25], and could promote higher rates of diabetes and cardiovascular disease throughout the lifespan.

Our finding that higher birth weight is associated with a higher FFMI is consistent with studies that report a positive relationship between birth weight and fat-free mass, as reviewed by Wells et al. [26]. However, we also show that including physical activity in the models attenuates the contribution of birth weight to FFMI. Most studies have not included physical activity in studies of relationship, and those that did were unable to report precise measures of fatfree mass [27]. Including this and other environmental covariates allowed us to further elucidate the contributions of early life versus current environment on body composition. In addition, SES is related to negative health outcomes in children and adults, and in our study higher SES is associated with lower FMI and trunk FMI [28,29]. Hence, including a combination of biological and environmental covariates in the model allowed us to more accurately assess the association of birth weight with FFMI, FMI, and trunk FMI, and this approach should be considered for future studies evaluating the effects of birth weight on health outcomes.
This study benefited from the use of more precise measures of body composition from DXA analysis that allowed us to calculate height-adjusted indices for fat and fat-free mass compartments. Inclusion of three ethnicities and both sexes also allowed us to adjust for the known ethnic and sexrelated differences in body composition. Of note, our results indicate differing associations of AA and HA with measures of adiposity, indicating that additional research is needed to determine whether birth weight affects future body composition differently among differing racial/ethnic groups. It is also possible that the lack of association between body composition and dietary factors in this study is due to use of a smaller sample size than is typically utilized in diet association studies. However, these results indicate that birth weight is associated with differences in pediatric body composition, and through this propensity for increased fat mass could indirectly contribute to increased chronic disease risk.

\section{CONCLUSION}

This study suggests that birth weight is positively associated with pediatric adiposity and fat-free mass as measured by DXA. Additional factors, such as racial ancestry, current socioeconomic status and physical activity, can also influence body composition and should be considered when evaluating the relationship of prenatal growth (birth weight) to childhood body mass. Understanding of the prenatal environment's relationship to future disease risk is essential to design effective interventions to decrease the rate of high birth weight babies born, and to identify older children at risk for excess adiposity.

\section{ACKNOWLEDGEMENTS}

This work was funded by the National Institutes of Health grants R01-DK067426, P30-DK56336, and M01-RR00032. A.L.W. was supported by the National Cancer Institute Cancer Prevention and Control Training Program (NIH CA 47888). The AMERICO team would like to thank Robert Petri for his assistance with body composition measurements.

\section{FUNDING SOURCES}

National Institutes of Health grants R01-DK067426, P30DK56336, and M01-RR-00032; NIH National Cancer Institute CA47888.

\section{REFERENCES}

[1] Adams KF, Schatzkin A, Harris TB, et al. Overweight, obesity, and mortality in a large prospective cohort of persons 50 to 71 years old. N Engl J Med 2006; 355: 763-78.

[2] Thearle MS, Bunt JC, Knowler WC, Krakoff J. Childhood predictors of adult acute insulin response and insulin action. Diabetes Care 2009; 32: 938-43.

[3] Ekelund U, Ong K, Linne Y, et al. Upward weight percentile crossing in infancy and early childhood independently predicts fat mass in young adults: the Stockholm Weight Development Study (SWEDES). Am J Clin Nutr 2006; 83: 324-30.

[4] Barker DJ, Eriksson JG, Forsen T, Osmond C. Fetal origins of adult disease: strength of effects and biological basis. Int $\mathrm{J}$ Epidemiol 2002; 31: 1235-9. 
[5] Barker DJ, Hales CN, Fall CH, Osmond C, Phipps K, Clark PM. Type 2 (non-insulin-dependent) diabetes mellitus, hypertension and hyperlipidaemia (syndrome $\mathrm{X}$ ): relation to reduced fetal growth. Diabetologia 1993; 36: 62-7.

[6] Harder T, Rodekamp E, Schellong K, Dudenhausen JW, Plagemann A. Birth weight and subsequent risk of type 2 diabetes: a meta-analysis. Am J Epidemiol 2007; 165: 849-57.

[7] Parsons TJ, Power C, Logan S, Summerbell CD. Childhood predictors of adult obesity: a systematic review. Int J Obes Relat Metab Disord 1999; 23(Suppl 8): S1-107.

[8] Eriksson J, Forsen T, Tuomilehto J, Osmond C, Barker D. Size at birth, childhood growth and obesity in adult life. Int J Obes Relat Metab Disord 2001; 25: 735-40.

[9] Whitaker, RC. Predicting preschooler obesity at birth: the role of maternal obesity in early pregnancy. Pediatrics 2004; 114: e29-e36.

[10] Chomtho S, Wells JC, Williams JE, Lucas A, Fewtrell MS. Associations between birth weight and later body composition: evidence from the 4-component model. Am J Clin Nutr 2008; 88: 1040-8.

[11] Chomtho S, Wells JC, Williams JE, Davies PS, Lucas A, Fewtrell MS. Infant growth and later body composition: evidence from the 4-component model. Am J Clin Nutr 2008; 87: 1776-84.

[12] Wells JC. A critique of the expression of paediatric body composition data. Arch Dis Child 2001; 85: 67-72.

[13] Wells JC. A Hattori chart analysis of body mass index in infants and children. Int J Obes Relat Metab Disord 2000; 24: 325-9.

[14] Wells JC, Cole TJ. Adjustment of fat-free mass and fat mass for height in children aged 8 y. Int J Obes Relat Metab Disord 2002; 26: $947-52$.

[15] Ekelund U, Sarnblad S, Brage S, Ryberg J, Wareham NJ, Aman J. Does physical activity equally predict gain in fat mass among obese and nonobese young adults? Int J Obes (Lond) 2007; 31: 65-71.

[16] Vimaleswaran KS, Li S, Zhao JH, et al. Physical activity attenuates the body mass index-increasing influence of genetic variation in the FTO gene. Am J Clin Nutr 2009; 90: 425-8.

[17] Chichlowska KL, Rose KM, ez-Roux AV, Golden SH, McNeill

AM, Heiss G. Life course socioeconomic conditions and metabo- lic syndrome in adults: the atherosclerosis risk in communities (ARIC) study. Ann Epidemiol 2009; 19(12): 875-83.

[18] Marshall WA, Tanner JM. Variations in the pattern of pubertal changes in boys. Arch Dis Child 1970; 45: 13-23.

[19] Marshall WA, Tanner JM. Variations in pattern of pubertal changes in girls. Arch Dis Child 1969; 44: 291-303.

[20] Hollingshead AB. Four factor index of social status. Unpublished Doctoral Dissertation 1975; 1-24.

[21] Wood AC, Kuntsi J, Asherson P, Saudino KJ. Actigraph data are reliable, with functional reliability increasing with aggregation. Behav Res Methods 2008; 40: 873-8.

[22] Fuiano N, Rapa A, Monzani A, et al. Prevalence and risk factors for overweight and obesity in a population of Italian schoolchildren: a longitudinal study. J Endocrinol Invest 2008; 31: 979-84.

[23] Yu Z, Sun JQ, Haas JD, Gu Y, Li Z, Lin X. Macrosomia is associated with high weight-for-height in children aged 1-3 years in Shanghai, China. Int J Obes (Lond) 2008; 32: 55-60.

[24] Hirschler V, Aranda C, Calcagno ML, Maccalini G, Jadzinsky M. Can waist circumference identify children with the metabolic syndrome? Arch Pediatr Adolesc Med 2005; 159: 740-4.

[25] Wahrenberg H, Hertel K, Leijonhufvud BM, Persson LG, Toft E, Arner P. Use of waist circumference to predict insulin resistance: retrospective study. BMJ 2005; 330: 1363-4.

[26] Wells JC, Chomtho S, Fewtrell MS. Programming of body composition by early growth and nutrition. Proc Nutr Soc 2007; 66: 423-34.

[27] Zhang X, Liu E, Tian Z, et al. High birth weight and overweight or obesity among Chinese children 3-6 years old. Prev Med 2009; 49: 172-8.

[28] Glymour MM, Avendano M, Berkman LF. Is the 'stroke belt' worn from childhood?: risk of first stroke and state of residence in childhood and adulthood. Stroke 2007; 38: 2415-21.

[29] Kington RS, Smith JP. Socioeconomic status and racial and ethnic differences in functional status associated with chronic diseases. Am J Public Health 1997; 87: 805-10.

(C) Willig et al.; Licensee Bentham Open.

This is an open access article licensed under the terms of the Creative Commons Attribution Non-Commercial License (http: //creativecommons.org/licenses/bync/3.0/), which permits unrestricted, non-commercial use, distribution and reproduction in any medium, provided the work is properly cited. 